\title{
Monitoring recovery from rocuronium-induced neuromuscular block using acceleromyography at the trapezius versus the adductor pollicis muscle: an observational trial
}

\section{Monitorage de la récupération après bloc neuromusculaire induit par rocuronium au moyen d'une accéléromyographie du trapèze ou du muscle adducteur du pouce: une étude observationnelle}

\author{
Stefan Soltesz, MD • Christian Stark, MD • Karl G. Noé, MD • Michael Anapolski, MD • \\ Thomas Mencke, MD \\ Received: 29 May 2015/Revised: 14 January 2016/Accepted: 2 February 2016/Published online: 10 February 2016 \\ (C) Canadian Anesthesiologists' Society 2016
}

\begin{abstract}
Purpose Positioning for surgery can restrict access to the patient's hand, thereby limiting assessment of the response at the adductor pollicis muscle to ulnar nerve stimulation. We evaluated a novel site to assess neuromuscular block by stimulating the accessory nerve and measuring the acceleromyographic response at the trapezius muscle.

Methods In this prospective non-blinded observational study, we assessed neuromuscular transmission in anesthetized adult female patients undergoing elective laparoscopic gynecological surgery. We performed the assessment by simultaneous recording acceleromyographic responses with the TOF-Watch ${ }^{\circledR} S X$ monitor at both the right adductor pollicis and left trapezius muscles. The neuromuscular block was achieved using rocuronium 0.3 $m g \cdot \mathrm{kg}^{-1}$, and the repeatability, time course, and limits of agreement (Bland-Altman) of responses were compared at
\end{abstract}

S. Soltesz, MD $(\bowtie) \cdot$ C. Stark, MD

Department of Anesthesia and Intensive Care Medicine, KKH Dormagen, 41540 Dormagen, Germany

e-mail: Stefan.soltesz@kkh-ne.de

K. G. Noé, MD

Department of Obstetrics and Gynecology, University of WittenHerdecke, KKH Dormagen, Dormagen, Germany

M. Anapolski, MD

Department of Gynecology, KKH Dormagen, Dormagen, Germany

T. Mencke, MD

Department of Anesthesia and Intensive Care Medicine,

University of Rostock, Rostock, Germany the two recording sites. The primary endpoint was the $90 \%$ train-of-four (TOF) recovery time with other endpoints included the onset time of the block, maximum T1 depression, time to $25 \% \mathrm{T1}$ recovery, and recovery time course of the $T 1$ response and TOF ratio.

Results Thirty-six patients were enrolled with responses obtained from 27 subjects. The variability of baseline responses recorded at the trapezius muscle was larger than that recorded at the adductor pollicis muscle, as determined by their mean (SD) repeatability coefficients [twitch height T1, 6.1 (1.9)\% and 4.2 (1.6)\%, respectively; $P=0.001 ;$ TOF ratio, 6.2 (2.1)\% and 4.3 (1.7)\%, respectively; $P=0.001]$. The recorded responses showed relatively narrow limits of agreement. The onset time of the block was 0.3 min earlier at the trapezius muscle than at the adductor pollicis muscle [2.3 (0.8) min and 2.6 (0.7) min, respectively; $P=0.007]$, with limits of agreement ranging from $1.6 \mathrm{~min}$ earlier to $1.0 \mathrm{~min}$ later. The time to $25 \% \quad T 1$ recovery was 1.8 min earlier at the trapezius muscle than at the adductor pollicis muscle [18.2 (5.7) min and 20.0 (5.2) min, respectively; $P=0.039$ ], with limits of agreement ranging from $11.1 \mathrm{~min}$ earlier to 7.5 min later. Additionally, the time to achieve 90\% TOF ratio was 4.4 min earlier at the trapezius muscle than at the adductor pollicis muscle [32.6 (7.9) min and 37 (9.1) min, respectively; $P=0.004]$, with limits of agreement ranging from 18.4 min earlier to 9.7 min later.

Conclusions We conclude that recording evoked acceleromyographic responses at the trapezius muscle is an acceptable alternative when monitoring from the adductor pollicis muscle is compromised. Nevertheless, we caution that recording a $90 \%$ TOF response at the trapezius muscle may overestimate functional recovery 
from the neuromuscular blockade. This trial was registered at ClinicalTrials.gov identifier, NCT01849198.

\section{Résumé}

Objectif Le positionnement du patient pour une intervention chirurgicale peut limiter l'accès à sa main et donc l'évaluation de la réponse à une stimulation du nerf cubital au niveau de l'adducteur du pouce. Nous avons évalué un nouveau site pour le monitorage du bloc neuromusculaire en stimulant le nerf accessoire et en mesurant la réponse accéléromyographique du trapèze.

Méthodes Au cours de cette étude observationnelle prospective sans insu, nous avons évalué la transmission neuromusculaire chez des patientes anesthésiées subissant une chirurgie gynécologique programmée par voie laparoscopique. Cette évaluation a consisté à enregistrer simultanément les réponses électromyographiques de l'adducteur du pouce droit et du trapèze gauche avec le moniteur TOF-Watch ${ }^{\circledR}$ SX. Le bloc neuromusculaire a été obtenu avec du rocuronium $0,3 \mathrm{mg} \cdot \mathrm{kg}^{-1}$ et la reproductibilité, l'évolution dans le temps et les limites de concordance (Bland-Altman) ont été comparées au niveau des deux sites d'enregistrement. Le critère d'évaluation principal était le temps de récupération à $90 \%$ d'un train de quatre (TOF); les autres critères d'évaluation étaient notamment le délai d'installation du bloc, la dépression $T 1$ maximum, le temps de récupération à $25 \%$ de $\mathrm{Tl}$, l'évolution du temps de récupération de $\mathrm{Tl}$ et le rapport de TOF

Résultats Trente-six patientes ont été recrutées et les réponses ont été obtenues chez 27 d'entre elles. La variabilité des réponses initiales enregistrées pour le trapèze était supérieure à celle enregistrée pour l'adducteur du pouce, telle que déterminée par leurs coefficients moyens (ÉT) de répétabilité (respectivement: hauteur de la fibrillation T1, 6,1\% [1,9\%] et 4,2\% [1,6\%]; $P=0,001$; rapport TOF, respectivement: $6,2 \%$ [2,1\%] et 4,3\% [1,7\%]; $P=0,001]$. Les réponses enregistrées ont montré des limites de concordance relativement étroites. Le délai d'apparition du bloc a été de 0,3 minute plus court pour le trapèze que pour l'adducteur du pouce (respectivement: 2,3 [0,8] min et 2,6 [0,7] min; $P=0,007)$, avec des limites de concordance allant de 1,6 min plus tôt à 1,0 min plus tard. Le temps de récupération $T 1$ à $25 \%$ a été de 1,8 min plus tôt pour le trapèze que pour l'adducteur du pouce (respectivement: 18,2 [5,7] min et 20,0 [5,2] min; $P=0,039$ ), avec des limites de concordance allant de 11,1 min plus tôt à 7,5 min plus tard. De plus, le délai d'obtention d'un rapport TOF de $90 \%$ a été de 4,4 min plus tôt pour le trapèze que pour l'adducteur du pouce (respectivement: 32,6 [7,9] min et 37,0 [9,1] min; $P=0,004)$, avec des limites de concordance allant de 18,4 min plus tôt à 9,7 min plus tard.

Conclusions Nous concluons que les réponses accéléromyographiques évoquées enregistrées au niveau $d u$ trapèze constituent une méthode de remplacement acceptable quand le monitorage au niveau de l'adducteur $d u$ pouce est compromis. Néanmoins, nous mettons en garde, car l'enregistrement d'une réponse TOF à $90 \%$ du trapèze peut surestimer la récupération fonctionnelle du bloc neuromusculaire. Cette étude a été enregistrée sur le site www.clinicaltrials.gov sous le numéro NCT01849198.

Following reversal of neuromuscular blockade, the monitoring of evoked muscle contractions must deliver an accurate and reliable record of the degree of residual block in the muscles that control respiration and protect the airway. ${ }^{1-4}$ Recording the evoked adductor pollicis muscle contractions in response to ulnar nerve stimulation meets these objectives, and as a result, this approach is commonly used during general anesthesia. ${ }^{5,6}$ Nevertheless, the position of the patient for surgery can restrict access to the upper extremities and thereby make it difficult to monitor these responses. Alternative responses have been proposed, such as contractions of the flexor hallucis brevis, orbicularis oculi, or corrugator supercilii muscles, but all these courses of action have their disadvantages. With regard to monitoring, recovery is faster at the flexor hallucis brevis muscle than at the adductor pollicis muscle, and depending on patient positioning and draping, access may be restricted. ${ }^{7,8}$ As for evoked facial muscle responses, the relatively small contractions of the orbicularis oculi and the corrugator supercilii are difficult to distinguish and quantify. ${ }^{9}$ Furthermore, recovery from the neuromuscular block at the corrugator supercilii is faster than at the adductor pollicis. ${ }^{4}$ Finally, due to the close proximity of these facial muscles to the facial nerve, direct muscle stimulation may be hard to avoid and thus may provide unreliable information.

In this study, we examined a new site for acceleromyographic monitoring, the trapezius muscle, and compared the responses at the new site with those simultaneously recorded at the adductor pollicis muscle. The trapezius muscle offers the advantage of being readily accessible in patients positioned for surgery with their arms tucked at their sides. The purpose of the study was to compare the responses (i.e., repeatability, time course, and limits of agreement of neuromuscular block) at these two muscles under identical conditions. We hypothesized that recording responses at the trapezius is a reliable and clinically useful method for monitoring recovery from 
neuromuscular block. The primary outcome measurement was the $90 \%$ train-of-four (TOF) recovery time.

\section{Methods}

\section{Patient selection}

We undertook this prospective un-blinded single-centre observational study after obtaining local ethics committee approval (Ethikkommission der Ärztekammer Nordrhein, Düsseldorf, Germany, April 23, 2013; No 2013056). Following patient written informed consent, we recruited female patients (aged 18-65 yr, American Society of Anesthesiologists physical status I-III, weight $50-90 \mathrm{~kg}$ ) having elective laparoscopic gynecological surgery under general anesthesia $(n=36)$.

Exclusion criteria included an expected difficult tracheal intubation (i.e., history of prior difficult intubation, reduced mouth opening $<2 \mathrm{~cm}$, and a Mallampati score of 4), increased risk of pulmonary aspiration (i.e., gastroesophageal reflux, full stomach, intestinal obstruction), known allergies to anesthetic drugs, pregnancy, neuromuscular disorders, intake of drugs affecting neuromuscular block (e.g., furosemide, magnesium, or cephalosporins), and hepatic (serum bilirubin $>26 \mu \mathrm{mol} \cdot \mathrm{L}^{-1}$ ) or renal (serum creatinine $>$ $90 \mu \mathrm{mol} \cdot \mathrm{L}^{-1}$ ) insufficiency.

\section{Induction and maintenance of anesthesia}

Patients were pre-medicated with midazolam $7.5 \mathrm{mg}$ per os and pre-oxygenated with $100 \% \mathrm{O}_{2}$ via a tightly fitted face mask. Anesthesia was induced with an intravenous infusion of remifentanil $0.2 \mu \mathrm{g} \cdot \mathrm{kg}^{-1} \cdot \mathrm{min}^{-1}$ and single bolus doses of fentanyl $2 \mu \mathrm{g} \cdot \mathrm{kg}^{-1}$ and propofol $2-3 \mathrm{mg} \cdot \mathrm{kg}^{-1}$. Following initial insertion of an $\mathrm{Ambu}^{\circledR}$ AuraOnce $^{\mathrm{TM}}$ size-4 laryngeal mask (Ambu Inc., Glen Burnie, MD, USA), anesthesia was maintained by an infusion of remifentanil $0.15-0.25 \mu \mathrm{g} \cdot \mathrm{kg}^{-1} \cdot \mathrm{min}^{-1}$ and propofol $3-5$ $\mathrm{mg} \cdot \mathrm{kg}^{-1} \cdot \mathrm{hr}^{-1}$. A Rüsch ${ }^{\circledR} 7.0-\mathrm{mm}$ internal diameter endotracheal tube (Teleflex ${ }^{\circledR}$ Ruschelit ${ }^{\mathrm{TM}}$ Medical, Athlone, Ireland) eventually replaced the laryngeal mask after establishment of the neuromuscular block (below). Patients' lungs were mechanically ventilated (respiratory rate, $10-12$ breaths $\cdot \mathrm{min}^{-1}$; tidal volume, $6-8 \mathrm{~mL} \cdot \mathrm{kg}^{-1}$ ) to achieve normocapnia (end-tidal $\mathrm{CO}_{2}$ concentration, 36-40 $\mathrm{mmHg}$ ), and heart rate and systemic arterial blood pressure were maintained within $20 \%$ of baseline values during the study. Nasopharyngeal and skin surface (at the adductor pollicis) temperatures were measured and kept above $36^{\circ} \mathrm{C}$ and $34^{\circ} \mathrm{C}$, respectively, by warm blankets or a Bair Hugger ${ }^{\circledR}$ Model 505 convective warming unit (Augustine Medical. Inc., MN, USA).
We assessed neuromuscular transmission following induction of anesthesia and insertion of the laryngeal mask by simultaneously recording acceleromyographic responses with the TOF Watch ${ }^{\circledR}$ SX monitor (Essex Pharma GmbH, Munich, Germany) at both the right adductor pollicis and the left trapezius muscles. Electrical stimulation of the ulnar and accessory nerves was achieved using transcutaneous silver-silver chloride $(\mathrm{Ag} / \mathrm{AgCl})$ electrodes for electrocardiography (Ambu Inc., MD, USA) placed over the right ulnar nerve at the wrist and 1 $\mathrm{cm}$ dorsal to the inferior border of the left sternocleidomastoid muscle, respectively (Fig. 1). The distance between the stimulating electrodes was $2 \mathrm{~cm}$. A response exhibited by adduction of the thumb verified stimulation of the ulnar nerve. To minimize erroneous responses associated with inadvertent movement of the upper extremity, the right hand was carefully fixed with tape to an arm board while the thumb was free to move. ${ }^{5}$ Due to the considerable distance between the ulnar nerve stimulation electrodes and the thumb, direct stimulation of the adductor pollicis was considered unlikely. A response exhibited by ipsilateral shoulder movement ("shrug") in a cranial direction verified appropriate stimulation of the accessory nerve. Care was taken to keep the patient's head in a neutral position throughout the study. The electrodes were moved slightly posteriorly to prevent inadvertent stimulation of the phrenic nerve (i.e., diaphragmatic contractions producing visible abdominal movements) or direct or indirect (accessory nerve) stimulation of the sternocleidomastoid muscle (i.e., turning of the head). To avoid direct stimulation of the trapezius muscle, care was taken to affix the electrodes ventral to its anterior border.

For acceleromyographic monitoring of muscle contractions, the accelerometer's piezoelectric element was fixed to the distal portion of the patient's right thumb ${ }^{5}$ and over the left trapezius muscle approximately $10 \mathrm{~cm}$ distal from the electrodes (Fig. 1). To establish a control twitch height value of $100 \%$, the acceleromyographs were calibrated/referenced to deliver a supramaximal TOF stimulus $(0.2 \mathrm{~Hz}$ every $15 \mathrm{sec}$, duration $0.1 \mathrm{msec}$ ). The TOF Watch SX possesses a calibration function that automatically determines the individual supramaximal stimulation current (up to a maximum current of $60 \mathrm{~mA}$ ). The maximal acceleromyographic response is automatically stored and serves as a reference control value for all subsequent measurements. ${ }^{10}$ The first of the four twitch height responses was considered $\mathrm{T} 1$, and the TOF ratio was the ratio of the fourth twitch (T4) height response to that of $\mathrm{T} 1$. During the first minute of stimulation, the acceleromyographic signal frequently drifts because the electric current leads to changes in the impedance of the $\mathrm{Ag} / \mathrm{Cl}$ electrodes. Therefore, after a ten-minute period of stabilization, both acceleromyographs were recalibrated. Ten consecutive T1 and TOF ratio values were then simultaneously recorded at 
Fig. 1 Placement of the electrodes and the acceleration transducer (white arrow) for stimulation of and recording from the trapezius muscle. Blue lines $=$ sternocleidomastoid muscle; Red line = anterior border of the trapezius muscle; Yellow lines $=$ accessorius nerve

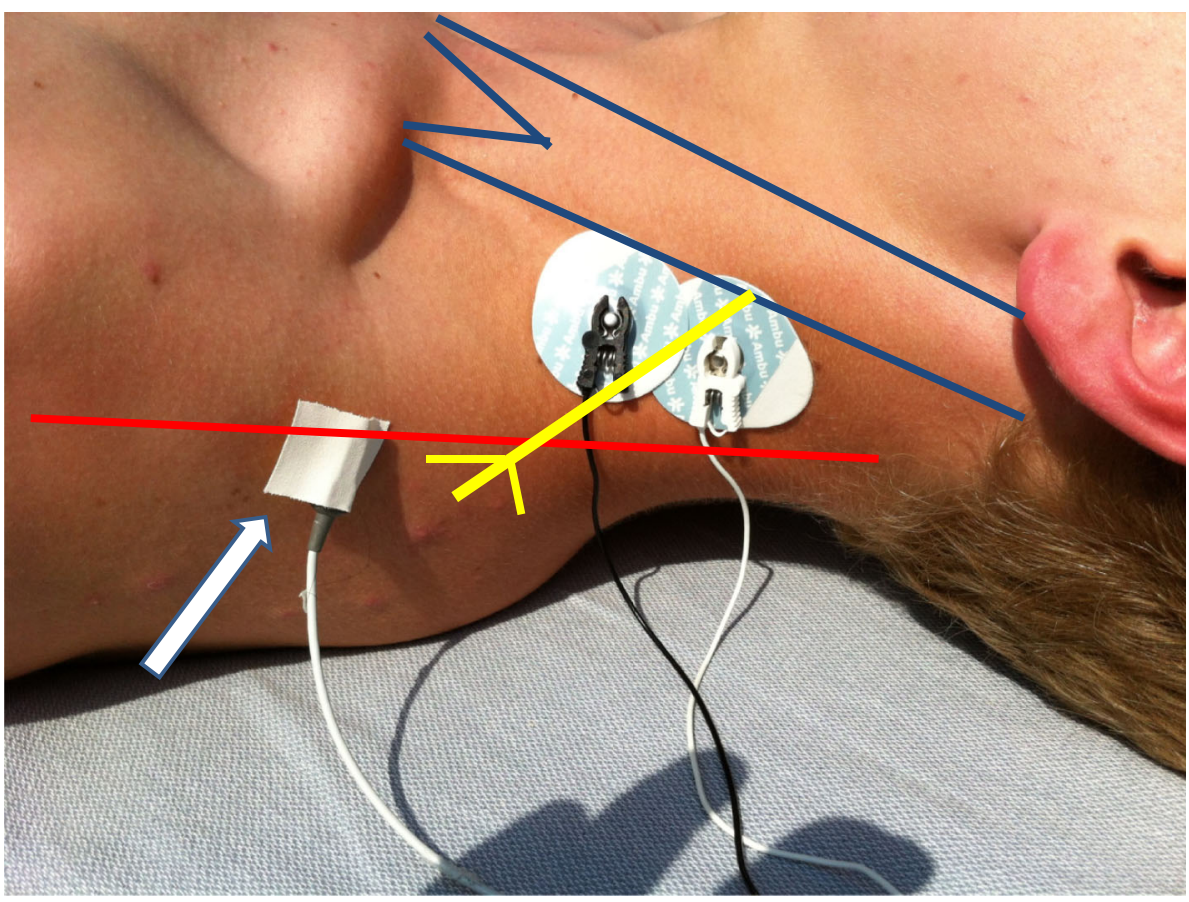

In each patient, ten consecutive measurements of $\mathrm{T} 1$ and TOF ratio at both measurement sites were simultaneously recorded prior to injection of rocuronium. The repeatability of these measurements was assessed using the withinindividual measurements that were analyzed by means of a one-way analysis of variance. The individual repeatability coefficients (calculated as $1.96 \sqrt{ } 2 \mathrm{SD})^{5,11,12}$ for all patients were compared between both measurement sites with a paired Student's $t$ test. At each recording site, onset of neuromuscular block, time to $25 \% \mathrm{~T} 1$ recovery, and time to $90 \%$ TOF recovery were compared with a paired Student's $t$ test. These responses were used to calculate their differences and limits of agreement according to BlandAltman analysis. ${ }^{11}$

The study sample size was calculated assuming a power of $80 \%$ to detect a $5 \%$ difference in time to $90 \%$ TOF recovery, with a type 1 error of 0.05 and an anticipated TOF ratio SD of $8 \%$. Accordingly, we required 23 patients for the study. In order to compensate for possible dropouts and because the expected SD was only an estimation, we enrolled 36 patients. ${ }^{13}$

\section{Results}

We enrolled 36 patients [age, 43 (7) yr; weight, 69 (8) kg; height, $167(5) \mathrm{cm}$ ] in the study during June 2013 to October 2014 (Fig. 2). Eight patients were excluded because the acceleromyographic signals were unstable or drifted at the trapezius muscle $(n=4)$, the adductor pollicis muscle $(n=2)$, or both $(n=2)$. In one patient, recording of 
responses was stopped because stimulation of the accessory nerve (and corresponding trapezius muscle) evoked diaphragmatic contractions and interfered with the surgery. In one patient, maximal $\mathrm{T} 1$ depression did not fall below $25 \%$ of the baseline value at the trapezius muscle, making it impossible to determine the time to $25 \%$ T1 recovery. Nevertheless, recovery to a 0.9 TOF ratio could still be measured in this patient. Therefore, 28 patients were included for measurement of recovery to a

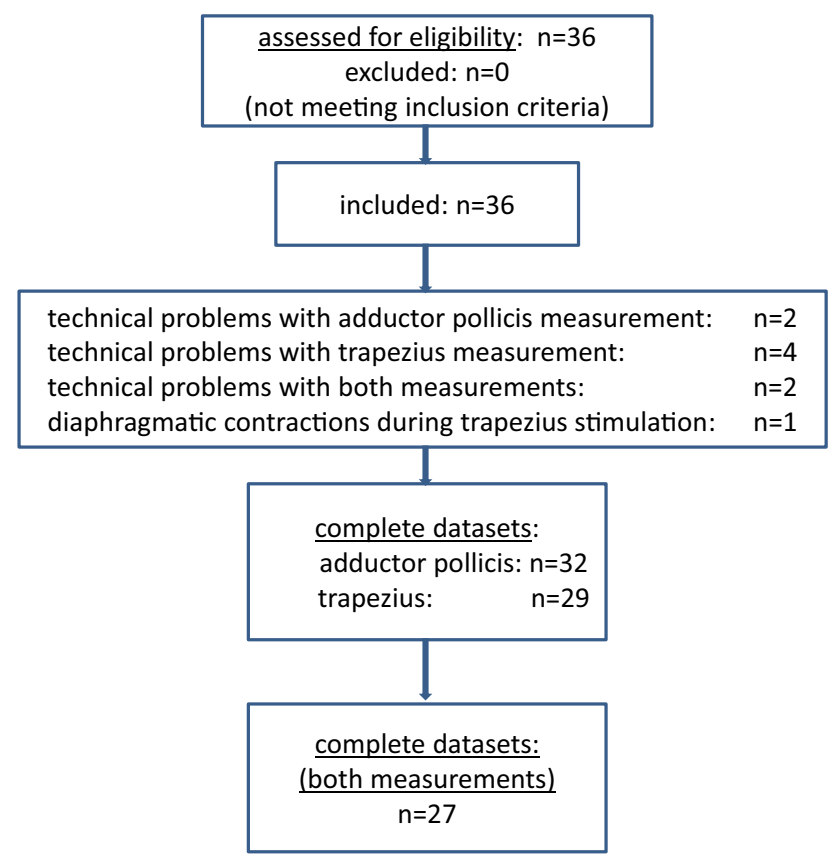

Fig. 2 Flow chart of patient selection
TOF ratio of 0.9 , and 27 patients were included for measurement of the time to $25 \% \mathrm{~T} 1$ recovery (Table).

\section{Baseline responses}

The supramaximal stimulation current was 50 (12) $\mathrm{mA}$ at the trapezius muscle and 48 (11) $\mathrm{mA}$ at the adductor pollicis muscle (mean difference, $1.9 \mathrm{~mA}$; $95 \%$ confidence interval $[\mathrm{CI}],-2.6$ to 6.4 ). Prior to rocuronium administration, the baseline TOF ratio values were $97 \%$ for the trapezius muscle and $108 \%$ for the adductor pollicis muscle (mean difference, $-12.1 \%$; 95\% CI, -15.9 to $-8.3 ; P<0.001)$. The repeatability coefficient of baseline $\mathrm{T} 1$ responses recorded at the trapezius muscle was higher than that recorded at the adductor pollicis muscle [6.1 (1.9)\% vs 4.2 (1.6)\%, respectively; mean difference, $1.9 \%$; $95 \% \mathrm{CI}, 1.1$ to 2.7]. Additionally, the repeatability coefficient of baseline TOF ratios was higher at the trapezius muscle than at the adductor pollicis muscle [6.2 (2.1)\% vs 4.3 (1.7)\%; mean difference, 1.9\%; 95\% CI, 1.0 to 2.8 ].

\section{Onset and maximal neuromuscular block}

The time course of T 1 and the TOF ratio are shown in Figs $3 \mathrm{a}$ and $3 \mathrm{~b}$. Following injection of rocuronium, block onset (rocuronium injection-maximum $\mathrm{T} 1$ depression interval) was recorded slightly earlier at the trapezius muscle than at the adductor pollicis muscle [2.3 (0.8) $\mathrm{min}$ vs $2.6(0.7) \mathrm{min}$, respectively; $P=0.007$; mean difference, $-0.3 \mathrm{~min} ; 95 \% \mathrm{CI}$, -0.5 to -0.1$]$. The $\mathrm{T} 1$ twitch heights at maximum block were similar [2.3 (6.3)\% vs $2.4(3.3) \%$ baseline, respectively;

Table Time course of the neuromuscular blockade

\begin{tabular}{|c|c|c|c|c|}
\hline & $\begin{array}{l}\text { Onset } \\
(\mathrm{min})\end{array}$ & $\begin{array}{l}\text { Twitch height } \\
\text { (\% T1 height) }\end{array}$ & $\begin{array}{l}\text { Duration } \\
\text { (min) }\end{array}$ & $\begin{array}{l}\text { TOF } 0.9 \\
(\mathrm{~min})\end{array}$ \\
\hline & mean $(\mathrm{SD})$ & mean $(\mathrm{SD})$ & mean $(\mathrm{SD})$ & mean (SD) \\
\hline \multirow[t]{3}{*}{ Trapezius } & $2.3^{*}$ & 2.3 & $18.2^{*}$ & $32.6^{*}$ \\
\hline & $(0.8)$ & (6.3) & $(5.7)$ & (7.9) \\
\hline & $n=36$ & $n=36$ & $n=27$ & $n=28$ \\
\hline Adductor & 2.6 & 2.4 & 20.0 & 37.0 \\
\hline \multirow[t]{2}{*}{ Pollicis } & $(0.7)$ & (3.3) & $(5.2)$ & $(9.1)$ \\
\hline & $n=36$ & $n=36$ & $n=27$ & $n=28$ \\
\hline \multirow[t]{2}{*}{ Difference $(95 \% \mathrm{CI})$} & -0.3 & -0.2 & -1.8 & -4.3 \\
\hline & -0.5 to -0.1 & -2.0 to 1.7 & -3.6 to -0.1 & -0.7 to -1.5 \\
\hline$P$ value & 0.007 & 0.857 & 0.039 & 0.004 \\
\hline
\end{tabular}

Onset $=$ time from the beginning of the injection of rocuronium to maximum $\mathrm{T} 1 \mathrm{depression}$; Twitch height $=$ twitch height in percent compared with baseline values; Duration = time from administration of rocuronium to recovery to $25 \%$ twitch height; TOF $0.9=$ time from injection of rocuronium to $90 \%$ train-of-four recovery; Difference $=$ mean difference between measurements; $95 \% \mathrm{CI}=95 \%$ confidence interval between both measurements; $n=$ number of successful measurements. $* P<0.05$ for trapezius $v s$ adductor pollicis 

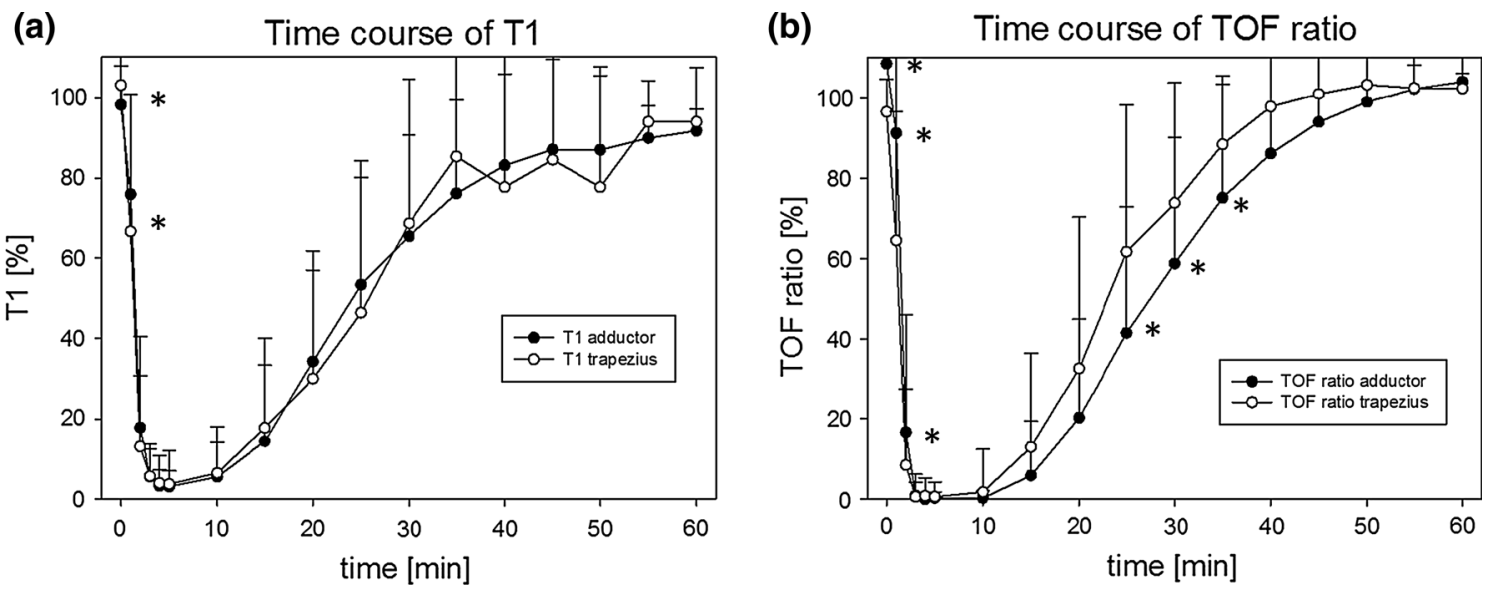

Fig. 3 a and b Time course of T1 and train-of-four ratio $v s$ time for both measurement sites. Rocuronium was injected at time " 0 ". Black dots = adductor pollicis muscle; White dots $=$ trapezius muscle. ${ }^{*} P<0.05$ for adductor pollicis $v s$ trapezius

(a) onset

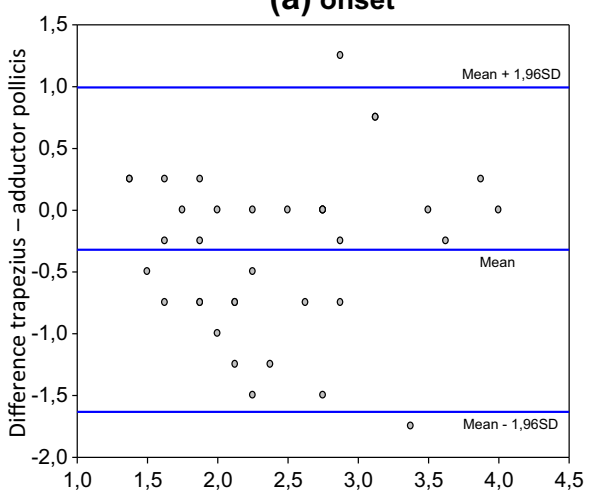

(b) duration

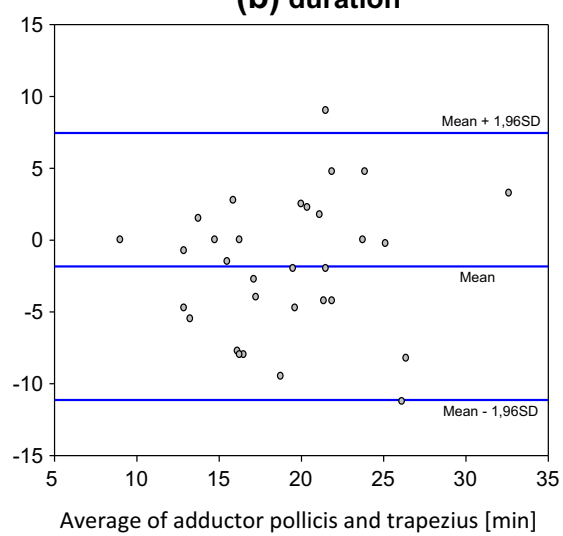

(c) TOF 0.9

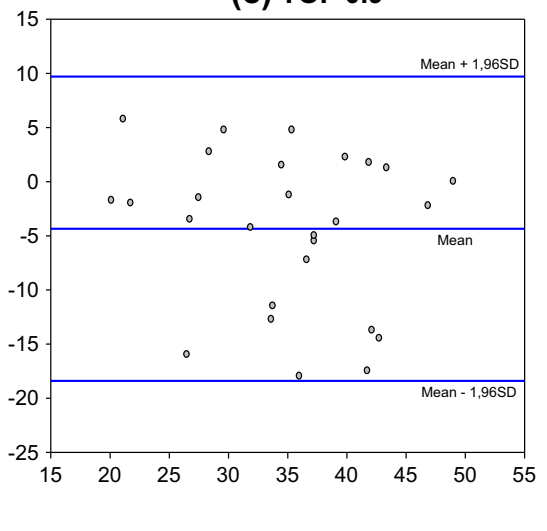

Fig. 4 a-c Bland-Altman plots of the differences between trapezius and adductor pollicis acceleromyographic responses. Black horizontal line in the middle = bias; Blue upper and lower line $=$ limits of agreement $( \pm 1.96 \mathrm{SD})$; a) Onset $=$ time $(\mathrm{min})$ from the beginning of

mean difference, $-0.2 \% ; 95 \% \mathrm{CI},-2.0$ to 1.7$]$. The TOF ratios at maximum block did not differ [0.6 (3.7)\% vs 0.3 (1.5)\%; mean difference, $0.3 \%$; $95 \% \mathrm{CI},-1.0$ to 1.7$]$.

Recovery from neuromuscular block

The time to recovery from the neuromuscular block to achieve $25 \% \mathrm{~T} 1$ recovery was somewhat shorter at the trapezius muscle than at the adductor pollicis muscle [18.2 (5.7) min vs 20.0 (5.2) min, respectively; mean difference, $-1.8 \mathrm{~min} ; 95 \% \mathrm{CI},-3.6$ to $-0.1 ; P=0.039]$. Additionally, recovery to a 0.9 TOF ratio was faster at the trapezius muscle than at the adductor pollicis muscle [32.6 (7.9) min vs 37.0 (9.1) $\mathrm{min}$, respectively; mean difference, $-4.3 \mathrm{~min}$; $95 \% \mathrm{CI},-0.7$ to $-1.5 ; P=0.004]$. At the time point when a 0.9 TOF ratio was measured at the trapezius muscle, the corresponding TOF ratio recorded at the adductor pollicis the injection of rocuronium to maximum T1 depression; b) Time $(\mathrm{min})$ to $25 \% \mathrm{~T} 1$ recovery $=$ time from administration of rocuronium to recovery to $25 \%$ twitch height; c) TOF $0.9=$ time (min) from injection of rocuronium to $90 \%$ train-of-four recovery

muscle was 0.8 (mean difference, $-14.0 \%$; $95 \%$ CI, -24.3 to -1.3 ) (Fig. 3b).

\section{Agreement}

The differences and limits of agreement between both measurement sites are illustrated according to BlandAltman analysis in Fig. 4a-c. Times to onset of block, $25 \% \mathrm{~T} 1$ recovery, and $0.9 \mathrm{TOF}$ ratio were faster at the trapezius muscle than at the adductor pollicis muscle. Onset of block was 0.3 min earlier at the trapezius muscle, with limits of agreement from $1.6 \mathrm{~min}$ earlier to $1.9 \mathrm{~min}$ later. Time to $25 \% \mathrm{~T} 1$ recovery was $1.8 \mathrm{~min}$ earlier at the trapezius muscle, with limits of agreement from $11.1 \mathrm{~min}$ earlier to $7.5 \mathrm{~min}$ later. Time to recovery to a 0.9 TOF ratio was 4.4 min earlier at the trapezius muscle, with limits of agreement from 18.4 min earlier to 9.7 min later. 


\section{Discussion}

In this study, a novel site, the trapezius muscle, was assessed as an appropriate location to monitor neuromuscular blockade. Although the reliability of the assessment of neuromuscular block at the trapezius muscle does not match that at the adductor pollicis muscle and indicates a somewhat faster onset and recovery time, we have shown that it may be considered an acceptable alternative if adductor pollicis monitoring is not feasible.

Appropriate monitoring of neuromuscular block is essential to maintain muscle relaxation during surgery and yet to ensure that reversal, with adequate return of respiratory function and protection of the airway, is feasible at the end of the procedure. ${ }^{14}$ While measurement of neuromuscular blockade at the adductor pollicis muscle is considered standard practice, ${ }^{5,6}$ this might be difficult in some cases because of limited access to the extremities. ${ }^{12}$ In clinical practice, a 0.9 TOF ratio recorded at the adductor pollicis muscle is considered to indicate adequate recovery from neuromuscular block..$^{1-4}$ Nevertheless, in this study, a TOF ratio of 0.9 recorded at the trapezius muscle corresponded to a TOF ratio of only about 0.8 at the adductor pollicis muscle. Therefore, in order to avoid inadequate reversal, we suggest cautious interpretation of TOF responses when monitoring neuromuscular block at the trapezius muscle. We emphasize that the relationship between neuromuscular measurements at the trapezius muscle and respiratory function and airway protection has yet to be determined.

One study similar to that described here investigated acceleromyographic responses evoked by electrical stimulation of the accessory nerve at the sternocleidomastoid muscle. One of the stimulating electrodes was placed directly over the midpoint of this muscle and the other was placed over the sternum. ${ }^{15}$ In that study, responses were also compared with those recorded at the adductor pollicis muscle. Similar to our observations, the sternocleidomastoid muscle required a higher supramaximal stimulation current than that at the adductor pollicis muscle, the amplitude of the neuromuscular block was lower, and the time to recovery from blockade was shorter. Drawbacks with the sternocleidomastoid recording site were the potential for direct muscle stimulation and the frequent (approximately $30 \%$ of patients) observation of evoked abdominal movement secondary to inadvertent stimulation of the phrenic nerve.

Technical problems occurred more frequently with the measurement at the trapezius muscle than at the adductor pollicis muscle. For example, while onset of the neuromuscular block was documented in all patients, the recovery measurement was impaired in seven (19\%) patients at the trapezius muscle compared with only four (11\%) patients at the adductor pollicis muscle. Nevertheless, this scientific analysis required a higher standard of recording artefact-free responses compared with routine clinical practice. In our view, the quality of responses in all 11 cases would have been sufficient for assessment of neuromuscular blockade in the routine clinical situation. Of importance, stabilization and calibration of the acceleromyograph requires substantial time and effort and is usually not performed in routine clinical cases. Nevertheless, non-calibrated acceleromyography shows acceptable clinical agreement with the calibrated technique. ${ }^{3}$

Stimulation of the accessory nerve as described may inadvertently evoke contractions of the diaphragm due to stimulation of the nearby phrenic nerve, located ventral to the scalenus anterior muscle. Diaphragmatic contractions may interfere with surgery, but this problem may be diminished by administration of additional muscle relaxant and/or decreasing the frequency of stimulation. This problem occurred with one patient during our study, and this patient had to be excluded as the research protocol demanded continuous stimulation every $15 \mathrm{sec}$ during the period of investigation. Another potential problem with using this recording site would be the requirement for steep Trendelenburg positioning and the need for shoulder pads to keep patients from sliding off the table. In this scenario, accessibility of the trapezius muscle would likely be limited.

We acknowledge that the dose of rocuronium administered in our investigation was rather low $(0.3$ $\left.\mathrm{mg} \cdot \mathrm{kg}^{-1}\right)$. In the clinical setting, neuromuscular block is usually achieved with an initial dose of $0.3 \mathrm{mg} \cdot \mathrm{kg}^{-1}$ for short procedures to $0.9 \mathrm{mg} \cdot \mathrm{kg}^{-1}$ in the case of a rapid sequence induction. Nevertheless, the use of small doses is recommended when assessing block onset and recovery, as large doses have a greater potential to be outside of the therapeutic range, exert indirect actions, and obscure subtle differential effects. ${ }^{5}$ On the other hand, for assessment of the recovery profile, it is suggested to achieve a T1 depression of at least $25 \%$. Therefore, we decided to use a dose of $0.3 \mathrm{mg} \cdot \mathrm{kg}^{-1}$ as a reasonable compromise to measure maximum block as well as to compare the recovery profile of both responses.

The within-individual standard deviations of the measurements as well as the corresponding repeatability coefficients were higher at the trapezius muscle than at the adductor pollicis muscle, suggesting that the former measurement site does not provide the same standard of precision as the latter. Nevertheless, the repeatability coefficients we recorded at the trapezius muscle are comparable with the data published in other studies 
concerned with acceleromyographic responses at the adductor pollicis muscle. ${ }^{12,16}$

It is well known that the time course of neuromuscular block can vary depending on the site of measurement of evoked responses. The onset is considerably faster at the larynx, ${ }^{17}$ diaphragm, ${ }^{1}$ and masseter muscle ${ }^{18,19}$ than at the adductor pollicis muscle. These differences may be related to variability in muscle perfusion. At rest, perfusion of the muscles of the upper extremity is low compared with muscles subserving respiration, which delays delivery of the neuromuscular blocking agent to the hand and the onset of block at that site. ${ }^{20}$ The recovery from neuromuscular block also varies widely. ${ }^{21}$ Several theories have been proposed for this variability, such as differences in perfusion, type of muscle fibre, or muscle diameter, ${ }^{2}$ but the underlying mechanism(s) remains speculative.

While the average differences between both measurement sites were relatively low (approximately 10$15 \%$ for all time intervals), the limits of agreement were in a higher range (e.g., approximately $-50 \%$ and $+30 \%$ ). Narrow limits of agreement suggest that the two methods of recording provide concordant results. In other studies that compared neuromuscular monitoring from the same muscle on each side, the observed ranges of limits of agreement were similar to those in our report. ${ }^{12,16}$ Taken together, these observations suggest that responses recorded at the adductor pollicis and trapezius muscles provide clinically similar information.

In summary, following administration of rocuronium, we compared the acceleromyographic responses recorded at the trapezius and adductor pollicis muscles. Given the similarities of responses with regard to repeatability, time course, and limits of agreement, we conclude that recording responses at the trapezius muscle is an acceptable alternative if monitoring at the adductor pollicis muscle is not feasible. Nevertheless, we caution that a 0.9 TOF ratio recorded at the trapezius may overestimate functional return from neuromuscular blockade.

\begin{abstract}
Author contributions: Stefan Soltesz, Christian Stark, and Thomas Mencke were involved in the study design and in the analysis of the data. Stefan Soltesz, Christian Stark, Karl G. Noé, and Michael Anapolski were involved in the conduct of the study. Stefan Soltesz, Christian Stark, Thomas Mencke, Karl G. Noé, and Michael Anapolski were involved in the preparation and revision of the manuscript.
\end{abstract}

Funding and conflicts of interest No person or persons other than the authors contributed significantly to the performance of this study. There were no financial supports or sponsorships, no commercial or non-commercial affiliations, and no other associations such as consultancies. None of the authors has any conflict of interest.

\section{References}

1. Cantineau JP, Porte $F$, d'Honneur $G$, Duvaldestin $P$. Neuromuscular effects of rocuronium on the diaphragm and adductor pollicis muscles in anesthetized patients. Anesthesiology 1994; 81: 585-90.

2. Hemmerling TM, Schmidt J, Hanusa C, Wolf T, Schmitt H. Simultaneous determination of neuromuscular block at the larynx, diaphragm, adductor pollicis, orbicularis oculi and corrugator supercilii muscles. Br J Anaesth 2000; 85: 856-60.

3. Schreiber JU, Mucha E, Fuchs-Buder T. Acceleromyography to assess neuromuscular recovery: is calibration before measurement mandatory? Acta Anaesthesiol Scand 2011; 55: 328-31.

4. Thilen SR, Hansen BE, Ramaiah R, Kent CD, GTreggiari MM, Bhananker SM. Intraoperative neuromuscular monitoring site and residual paralysis. Anesthesiology 2012; 117: 964-72.

5. Fuchs-Buder T, Claudius C, Skovgaard LT, et al. Good clinical research practice in pharmacodynamic studies of neuromuscular blocking agents II: the Stockholm revision. Acta Anaesthesiol Scand 2007; 51: 789-808.

6. Naguib M, Kopman AF, Lien CA, Hunter JM, Lopez A, Brull SJ. A survey of current management of neuromuscular block in the United States and Europe. Anesth Analg 2010; 111: 110-9.

7. Kern SE, Johnson JO, Orr JA, Westenskow DR. Clinical analysis of the flexor hallucis brevis as an alternative site for monitoring neuromuscular block from mivacurium. J Clin Anesth 1997; 9: 383-7.

8. Saitoh Y, Koitabashi Y, Makita K, Tanaka H, Amaha K. Train-offour and double burst stimulation fade at the great toe and thumb. Can J Anaesth 1997; 44: 390-5.

9. Plaud B, Debaene B, Donati $F$. The corrugator supercilii, not the orbicularis oculi, reflects rocuronium neuromuscular blockade at the laryngeal adductor muscles. Anesthesiology 2001; 95: 96101.

10. Martin-Flores M, Gleed RD, Basher KL, Scarlett JM, Campoy L, Kopman $A F$. TOF-Watch(R) monitor: failure to calculate the train-of-four ratio in the absence of baseline calibration in anaesthetized dogs. Br J Anaesth 2012; 108: 240-4.

11. Bland JM, Altman DG. Measuring agreement in method comparison studies. Stat Methods Med Res 1999; 8: 135-60.

12. Dubois PE, De Bel M, Jamart J, et al. Performance of acceleromyography with a short and light TOF-tube compared with mechanomyography: a clinical comparison. Eur J Anaesthesiol 2014; 31: 404-10.

13. Kopman AF, Chin W, Cyriac J. Acceleromyography vs. electromyography: an ipsilateral comparison of the indirectly evoked neuromuscular response to train-of-four stimulation. Acta Anaesthesiol Scand 2005; 49: 316-22.

14. Dubois PE, Putz L, Jamart J, Marotta ML, Gourdin M, Donnez $O$. Deep neuromuscular block improves surgical conditions during laparoscopic hysterectomy: a randomised controlled trial. Eur J Anaesthesiol 2014; 31: 430-6.

15. Saitoh $Y$, Oshima T, Nakata $Y$. Monitoring of vecuroniuminduced neuromuscular block at the sternocleidomastoid muscle in anesthetized patients. J Anesth 2010; 24: 838-44.

16. Claudius C, Skovgaard LT, Viby-Mogensen J. Arm-to-arm variation when evaluating neuromuscular block: an analysis of the precision and the bias and agreement between arms when using mechanomyography or acceleromyography. Br J Anaesth 2010; 105: 310-7.

17. Meistelman C, Plaud B, Donati F. Rocuronium (ORG 9426) neuromuscular blockade at the adductor muscles of the larynx and adductor pollicis in humans. Can J Anaesth 1992; 39: 665-9. 
18. Kitajima O, Suzuki T, Watanabe $N$, et al. Monitoring masseter muscle evoked responses enables faster tracheal intubation. $\mathbf{J}$ Anesth 2010; 24: 173-6.

19. Kitajima O, Suzuki T, Fukano N, Saeki S, Ogawa S, Noda Y. Onset of rocuronium-induced neuromuscular block evaluated subjectively and accerelomyographically at the masseter muscle. J Anesth 2011; 25: 376-9.
20. Bragg P, Fisher DM, Shi J, et al. Comparison of twitch depression of the adductor pollicis and the respiratory muscles. Pharmacodynamic modeling without plasma concentrations. Anesthesiology 1994; 80: 310-9.

21. Gavrancic B, Lolis A, Beric A. Train-of-four test in intraoperative neurophysiologic monitoring: differences between hand and foot train-of-four. J Clin Neurophysiol 2014; 31: 575-9. 